1 ANALYTICAL SCIENCE

4 \& TECHNOLOGY

Vol. 25, No. 5, 307-312, 2012

http://dx.doi.org/10.5806/AST.2012.25.5.307

\title{
Analysis of didecydimethylammonium chloride (DDAC) aerosol in inhalation chamber
}

\author{
Jeong-Sun Yang ${ }^{\star}$, Sung-Bong Choi, Sang-Yong Park and Sung-Bae Lee \\ Center for Chemicals Safety \& Health, Occupational Safety \& Health Research Institute, Daejeon 305-380, Korea \\ (Received June 25, 2012; Revised September 6, 2012; Accepted September 27, 2012)
}

\section{흡입챔버 내 didecyldimethylammonium chloride(DDAC) \\ 에어로졸의 분석}

양정선` · 최성봉 · 박상용 · 이성배

산업안전보건연구원 화학물질센터

(2012. 6. 25. 접수, 2012. 9. 6. 수정, 2012. 9. 27. 승인)

\begin{abstract}
To perform inhalation toxicity test by using experiment animals, we set up an analytical method to monitor didecyldimethylammonium chloride (DDAC) in aerosol nebulized into inhalation chambers by ion chromatography. DDAC was adsorbed by XAD-2 resin and analyzed with conductivity detector. Recovery of DDAC desorbed by acetonitrile from XAD adsorbent was $87.8 \%$. The method detection limit (MDL) and the limit of quantitation (LOQ) were $2.97 \mu \mathrm{g} / \mathrm{m}^{3}$ and $8.92 \mu \mathrm{g} / \mathrm{m}^{3}$, respectively. Repeatability was calculated as RSD $7.8 \%$ in the range of $0 \sim 20 \mu \mathrm{g} / \mathrm{mL}$. Time needed to analyze a sample was less than 5 minutes. Therefore, the analysis of DDAC by ion chromatography was practically useful in monitoring DDAC in inhalation chambers with rapidity and sensitivity manner to perform inhalation toxicity test using experimental animals.

요 약: 4급 암모늄 계열의 대표적인 살균제인 didecyldimethylammonium chloride(DDAC)는 흡입 경로 에 의해 폐 섬유화 등의 폐질환을 일으킬 가능성이 높은 물질로, 흡입독성시험을 위하여 전신 흡입노출 챔버 내에 에어로졸 형태로 분무된 $\mathrm{DDAC}$ 의 포집 및 분석방법을 검토하였다. $\mathrm{DDAC}$ 의 포집 회수율은 아세토니트릴을 사용하여 탈착한 XAD 흡착제의 회수율이 $87.8 \%$ 로 실리카겔의 경우보다 우수한 것으로 나타났다. 이온크로마토그라프-전기전도도 검출기로 분석한 DDAC의 검출한계(MDL, method detection limit)는 $0.18 \mu \mathrm{g} / \mathrm{mL}$ 이었으며, 정량한계(LOQ, limit of quantitation)는 $0.54 \mu \mathrm{g} / \mathrm{mL}$ 였다. 공기 포집 량 $240 \mathrm{~L}$ 를 기준으로 챔버 내 공기 중 농도로 환산하면 $\mathrm{MDL}$ 이 $2.97 \mu \mathrm{g} / \mathrm{m}^{3}, \mathrm{LOQ}$ 가 $8.92 \mu \mathrm{g} / \mathrm{m}^{3}$ 로, 챔버 내 발생 농도인 70 900 $\mu \mathrm{g} / \mathrm{m}^{3}$ 농도 수준의 모니터링에 적절하였다. 분석의 재현성은 $0 \sim 20 \mu \mathrm{g} / \mathrm{mL}$ 농도범위에서 상대오차 $7.8 \%$ 내외였으며 시료 분석에 소요되는 시간은 5 분 이내였다. 따라서 XAD를 사용한 DDAC 의 포집 및 이온크로마토그라피를 이용한 분석방법은 실험동물을 사용한 전신 흡입노출 챔버 내 DDAC 농도의 신속하고 편리한 모니터링에 적절한 것으로 나타났다.
\end{abstract}

Key words: DDAC, biocide aerosol, ion chromatography, inhalation chamber

Corresponding author

Phone : +82-(0)42-869-0341 Fax : +82-(0)42-863-9001

E-mail : yjs@kosha.net 


\section{1. 서 론}

Didecyldimethylammonium chloride (DDAC)는 4급 암모늄 계열의 대표적인 살균제로 $10 \sim 20 \%$ 용액으로 상품화되어 목재 가공시 곰팡이균의 억제 등을 위한 살균 소독제, 수영장이나 스파 등에서 소독용 첨가제, 가습기용 살균제의 성분 등으로 사용되어왔다. ${ }^{1} 2006$ 년 미국 환경청(EPA)의 보고서에 의하면 $\mathrm{DDAC}$ 는 240 2,400 ppm의 농도 수준에서 에어로졸 스프레이 형태로 병원 및 일반가정 등 청소용역, 방역작업 등에 서 사용되고 있으며, 0.5 2 ppm 수준에서 수영장 살 균제로, 5 938 ppm의 농도로 분수대 등의 물에 첨가 되고 있다. 산업계의 용도로써 $32 \sim 1,800 \mathrm{ppm}$ 의 농도 수준에서 산업용 냉각수 첨가제로 사용되며, 고압분무 형태로 표면처리 등 목재가공, 농업 부문에서 26,320 $\mathrm{ppm}$ 의 농도로 부화장 등에서 분무형태로 사용된다. ${ }^{2}$ 2006년 환경부의 국내 화학물질 유통량 자료에 의하 면 국내에서는 약 17 개 사업장에서 연 20.73톤이 사 용되는 것으로 보고되어 있다. ${ }^{3}$

$\mathrm{DDAC}$ 는 토끼 및 기니피그를 사용한 독성시험에서 피부자극을 종말점으로 하는 무독성량(NOAEL, noobserved-adverse effect level)이 $2 \mathrm{mg} / \mathrm{kg} / \mathrm{day}$ 로 피부 및 눈자극성 구분 2 에 해당하는 물질로 분류되었다. ${ }^{4}$ 개를 사용한 아급성 경구독성에서의 무독성량은 10 $\mathrm{mg} / \mathrm{kg} / \mathrm{day}$ 으로 보고되었다. ${ }^{5}$ Ohnuma 등6은 DDAC를 $1,500 \mu \mathrm{g} / \mathrm{kg}$ 의 농도로 마우스에 일회 기관지 투여하였 을 때, 기관지 염증 및 폐세포 섬유화가 관찰되었음을 보고하였다. 2006년 $\mathrm{EPA}$ 의 보고서에 따르면 $\mathrm{DDAC}$ 의 흡입독성 시험자료는 없으나 경구투여 시험으로부터 무독성량을 $100 \mathrm{mg} / \mathrm{kg} / \mathrm{day}$ 로 추정하였다. 그러나 호흡 기 표적장기독성을 일으킬 것으로 추정되는 경우 경구 독성 자료로부터 흡입에 의한 무독성량의 외삽은 가능 하지 않다. 이와 같이 에어로졸 스프레이 형태로 널리 사용되는 살균제는 폐가 일차적 표적장기로 폐 섬유화 등을 일으키며 흡입에 의한 건강장해의 잠재위험이 크 지만, 현재까지 이들 4급 암모늄 계열의 살균제에 대한 흡입독성 연구는 거의 이루어지지 않았다.

2011년 2월에서 4월 중 서울 시내에 있는 대형병원 에서 기존에 알려진 급성 간질성 폐렴과는 다른 종말 세기관지 염증 병변을 나타내는 흡입성 폐질환이 임 산부들에게 발생하여, 이러한 원인을 확인하기 위한 역학조사가 수행되었다. 환자들에 대해 심층 조사결과, 가습기 살균제 사용에 대한 대응 위험도가 통계적으 로 유의하게 나타나, 원인 미상의 폐질환이 가습기 살
균제의 흡입에 의한 것임을 의심하게 되었다. 이후에 추가적으로 동물을 사용한 흡입독성 시험이 수행되었 으며, 가습기 살균제 성분을 흡입한 쥐에서 종말 세기 관지 염증을 비롯한 폐질환이 관찰되었다. ${ }^{7}$ 이에 따라, 식품의약품안전청에서는 해당 제품에 대한 수거명령 을 내림으로써 가습기 사건에 대한 일련의 대응이 마 무리되었다. 이 사례는 흡입에 의한 독성평가 없이 무 독성, 무영향이 강조된 상태에서 본래의 사용법과는 다르게 살균제 성분이 가습기 액에 직접 혼합되고 이 것이 공기 중에 분무되어 폐로 직접 들어가서 예상하 지 못했던 유해성이 나타나게 된 경우이다. 살균제 성 분이 스프레이 형태로 분무되어 직접 폐로 들이마시 게 되는 경우 흡입독성시험을 통하여 위험성을 재평 가해야 한다. 이를 위해서는 실험동물을 사용한 흡입 독성 시험에 사용할 수 있는 목적 성분의 채취 및 분 석 방법이 제공되어야 한다.

따라서 본 연구에서는 실험동물용 전신 흡입노출 챔버 내에 발생시킨 에어로졸 중 $\mathrm{DDAC}$ 의 모니터링 을 위하여 흡입챔버 내 $\mathrm{DDAC}$ 에어로졸의 포집 및 포집 시료 중 $\mathrm{DDAC}$ 분석 조건을 검토하였다.

\section{2. 방 법}

\section{1. 기구 및 시약}

이온크로마토그라피용 이동상 용매로 아세토니트릴 (HPLC grade, J.T. Baker Inc., the Netherlands)과 황산 (>95\%, Aldrich, USA)을 사용하였다. 시료의 희석을 위하여 탈이온수 제조기(Millipore Co., USA)를 사용 하여 $18 \mathrm{M} \Omega$ ultra pure de-ionized water를 제조하여 사용하였다. DDAC 표준품 $99.3 \%$ Shin Won Chemtrade Co. LTD., China)은 시약용을 구매하여 사용하였다.

흡입챔버 내 DDAC 에어로졸의 포집 및 회수율 시 험을 위하여 silica gel 흡착튜브 $(10 \times 110 \mathrm{~mm}, 260 / 1040$ $\mathrm{mg} \mathrm{SiOH}, \mathrm{SKC}, \mathrm{USA}), \mathrm{XAD}-2$ resin 튜브$(8 \times 110 \mathrm{~mm}$, 200/400 mg XAD-2, SKC, USA)를 사용하였다.

\section{2. 전신 흡입노출 챔버}

전신 흡입노출 챔버(Model No. SIS-20RG SIBATA Co., LTD., Japan)는 OECD GLP 가이드라인에 의하 여 내부용적 $1.3 \mathrm{~m}^{3}$ 로 대조군, 저농도, 중농도, 고농도 군의 4 챔버로 구성되었으며 각 챔버는 미스트 발생 장치(Model No. VG-4R, SIBATA Co., LTD., Japan)와 연결되어 있다. 미스트 발생장치에서 발생된 DDAC 에어로졸과 청정공기를 일정비율로 조절하여 흡입챔 


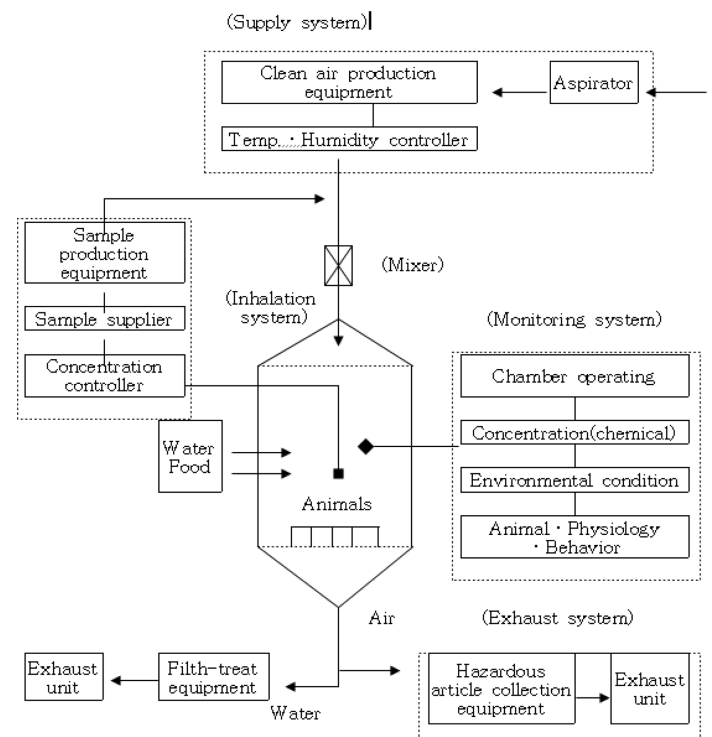

Fig. 1. Inhalation exposure system for animal experiment.

버 상부에 부착된 혼합장치를 이용하여 혼하였다(Fig. 1). HEPA 필터 및 온습도 조절장치를 부착한 공조기 에서 처리한 청정공기를 전신 흡입노출 챔버 내로 공 급하였으며 온도는 $22 \pm 3{ }^{\circ} \mathrm{C}$, 상대습도는 $50 \pm 20 \%$ 로 유지하였다.

\section{3. $\mathrm{DDAC}$ 에어로졸의 발생}

실험동물을 사용한 흡입노출 시험을 위하여 $\mathrm{DDAC}$ 의 독성자료를 참고하여 전신 흡입노출 챔버 내 $\mathrm{DDAC}$ 에어로졸의 농도를 저농도군 약 $100 \mu \mathrm{g} / \mathrm{m}^{3}$, 중농도군 약 $300 \mu \mathrm{g} / \mathrm{m}^{3}$, 고농도군 약 $900 \mu \mathrm{g} / \mathrm{m}^{3}$ 를 목 표농도로 설정하였다. $\mathrm{DDAC}$ 를 증류수에 희석하여 $0.5 \%$ 용액을 조제하고 미스트 발생장치를 통하여 유 속 $10 \sim 13 \mathrm{~L} / \mathrm{min}$ 로 내부용적 $1.3 \mathrm{~m}^{3}$ 인 전신 흡입노출

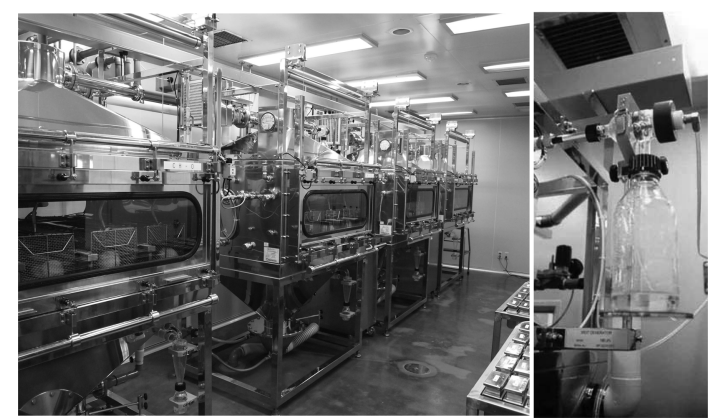

Fig. 2. Whole body inhalation chamber and aerosol generator.
챔버 내에 고압분사하였다(Fig. 2).

\section{4. 에어로졸 입경 분포}

에어로졸의 입경 분포는 Anderson sampler용 필 터(80 mm, Pallflex products, Japan)가 포함된 9단계의 Anderson sampler (Sibata, Impactor 200913, Japan) 를 이용하여 측정하였다. 흡입 챔버내 공기를 실험 동물의 호흡기 위치에서 $28.3 \mathrm{~L} / \mathrm{min}$ 의 유속으로 10 분간 포집하였다. 포집된 $\mathrm{DDAC}$ 에어로졸은 포집 전후의 필터 중량을 측정하여(Kern 770, Gemany) 확인하였다.

\section{5. 시료 포집 및 탈착}

전신 흡입노출 챔버 내의 실험동물 호흡기 위치에 연결된 개인시료채취기(Model No. Airchek XR 5000, SKC Inc., USA)에 XAD-2 resin 흡착튜브(SKC, 8x $110 \mathrm{~mm}, 200 / 400 \mathrm{mg}$ )를 부착하여 약 $1 \mathrm{~L} / \mathrm{min}$ 의 유속 으로 $120 \sim 240$ 분간 포집하였으며 포집 전후에 유량을 검량하였다. 포집한 시료는 $4{ }^{\circ} \mathrm{C}$ 에서 냉장보관 하였으 며 24시간 이내에 분석하였다. 흡착제의 탈착효율 검 정을 위하여 silica gel 흡착튜브(SKC, $10 \times 110 \mathrm{~mm}$, $260 / 1040 \mathrm{mg}$ ) 및 XAD-2 resin 흡착튜브에 각각 9.6 $\mathrm{mg} / \mathrm{mL} \mathrm{DDAC}$ 용액 2, 5, $10 \mu \mathrm{L}$ 를 마이크로시린지로 주입한 후 24시간 동안 데시케이터 안에 보관하였다. Silica gel 흡착제 및 XAD-2 resin 흡착제를 바이알에 옮긴 후 아세토니트릴 $4 \mathrm{~mL}$ 를 가하여 vortex mixer에 서 진탕 후 초음파세척기에서 30 분간 탈착하였다. 탈 착한 용액 각 $100 \mu \mathrm{L}$ 를 이온크로마토그라피에 주입 하였다. 각 흡착제의 탈착효율은 주입한 양과 탈착 후 분석한 결과를 비교하여 구하였다.

\section{6. 기기 및 분석조건}

본 연구에서 사용된 이온크로마토그라프는 Dionex 사의 AS50 모델로, AS50 Auto-sampler와 GP50 pump 를 사용하였다. 컬럼은 IonPac CG12A $(4 \times 50 \mathrm{~mm})$ 을 사용하였으며, Supressor는 Dionex CSRS 300(4 mm) 를 사용하였다. 이동상은 $30 \mathrm{mM}$ sulfuric acid와 아세 토니트릴을 3:7의 비율로 섞어서 사용하였으며 유속 은 $1.0 \mathrm{~mL} / \mathrm{min}$ 로 하였다. 시료는 아세토니트릴로 탈 착하여 $100 \mu \mathrm{L}$ 를 주입하였으며, Dionex ED50 전기전 도도 검출기를 사용하여 검출하였다. 검량선 작성을 위해 챔버 내에 주입한 $\mathrm{DDAC}$ 의 농도를 감안하여 0 $20.0 \mu \mathrm{g} / \mathrm{mL}$ 농도범위로 $\mathrm{DDAC}$ 의 아세토니트릴 용 액을 제조하였다.

Vol. 25, No. 5, 2012 


\section{3. 결과 및 고찰}

실험동물을 사용한 흡입노출 시험을 위하여 마우스 의 기관지 투여 경로에 의한 독성시험 자료 ${ }^{6}$ 로부터, $1500 \mu \mathrm{g} / \mathrm{kg}$ 의 농도에서 폐부종이 관찰되었음을 확인 하였다. 일회 기관지 투여량을 마우스 1 일 호흡량과 체중 및 13 주 반복노출시험에 대한 노출기간 보정계 수으로 보정하면, 독성 발현이 예측되는 흡입노출 농 도는 약 $0.36 \mathrm{mg} / \mathrm{m}^{3}$ 으로 환산된다. ${ }^{8}$ 따라서, 실험동물 에 대한 무영향농도 산정을 위한 흡입챔버내 DDAC 의 농도는 약 $0.36 \mathrm{mg} / \mathrm{m}^{3}$ 를 중농도로 설정하고, 저농 도는 중농도의 약 $1 / 3$ 인 $0.1 \mathrm{mg} / \mathrm{m}^{3}$ 내외, 고농도는 중 농도의 약 3 배인 $1.0 \mathrm{mg} / \mathrm{m}^{3}$ 내외로 설정하였다.

전신 흡입노출 챔버 내 에어로졸의 발생 목표농도 달성을 위하여 발생장치의 노즐의 개폐 정도를 조절 하여 유량을 검량하고 청정공기 유입율을 조정하여 최종 농도를 중농도를 중심으로 약 $300 \mu \mathrm{g} / \mathrm{m}^{3}$ 되도록 조절하였다. 전신 흡입노출 챔버에 분사된 $\mathrm{DDAC}$ 에 어로졸의 입경분포를 Anderson sampler를 사용하여 측정한 결과, 입경의 기하평균은 $1.23 \mu \mathrm{m}$ 이였으며 $0.43 \sim 4.70 \mu \mathrm{m}$ 인 호흡성 에어로졸이 $94.7 \%$ 이였다(Fig. 3). 전신 흡입노출 챔버 내의 실험동물 호흡기 위치에 연결한 개인시료 채취기를 이용하여 XAD-2 resin 흡 착튜브에 포집한 시료를 아세토니트릴로 탈착하여 이 온크로마토그라프로 분석하였다.

$\mathrm{DDAC}$ 는 디알킬 4급 암모늄으로 구조상 발색단을 포함하고 있지 않으므로(Fig. 4) HPLC 가시-자외부

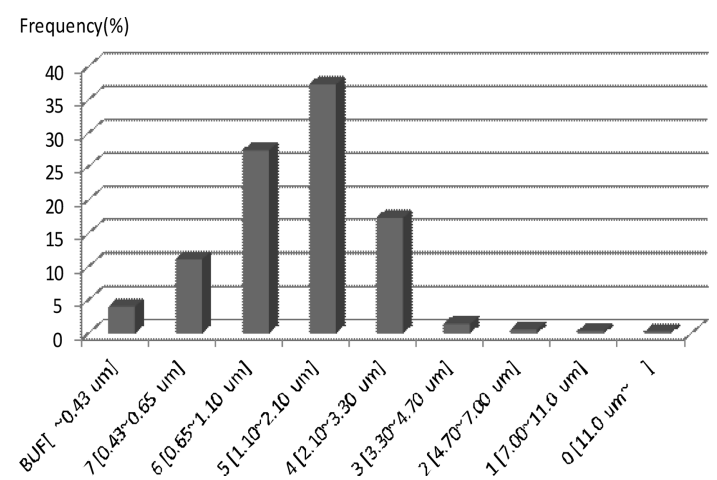

Fig. 3. Particle size distribution of DDAC aerosol in inhalation chamber.

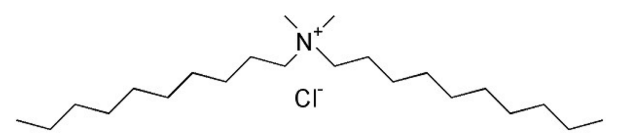

Fig. 4. Structure of DDAC.

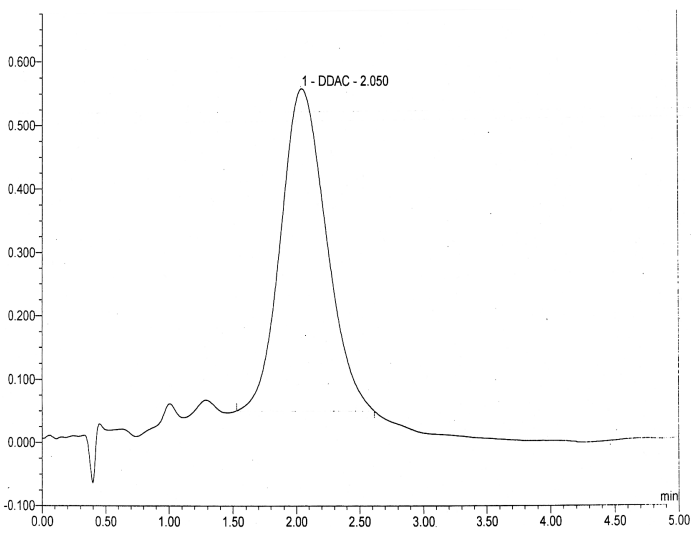

Fig. 5. Chromatogram of DDAC aerosol sample extracted by acetonitrile from XAD-2 resin (Dionex AS50 Ion Chromatograph, Column; IonPac CG12A $4 \times 50 \mathrm{~mm}$, Mobile phase; $30 \mathrm{mM}$ sulfuric acid:acetonitrile $=3: 7$, Flow rate; $1.0 \mathrm{~mL} / \mathrm{min}$, Injection volume; $100 \mu \mathrm{L}$, Dionex ED50 Conductivity Detector, Supressor; Dionex CSRS 300, $4 \mathrm{~mm}$ ).

검출기로 검출되지 않는다. 전신 흡입노출 챔버 내에 발생시킨 DDAC 에어로졸의 농도는 가능한 한 신속 하게 분석하여 유량을 검량할 필요가 있으므로 본 연 구에서는 전신 흡입노출 챔버에서 포집한 시료의 탈착 액을 시험방법에서 제시한 조건에서 전도도 검출기가 부착된 이온크로마토그라피를 통하여 분석하였다. 컬럼 은 IonPac CG12A(4×50 mm)를 사용하였으며 제시한 조건에서 $\mathrm{DDAC}$ 피크는 2.05 2.12분 사이에 용출되었 다. 공존하는 방해피크의 영향은 없었다(Fig. 5).

$0 \sim 20.0 \mu \mathrm{g} / \mathrm{mL}$ 농도범위에서 회귀분석 방법을 통하 여 얻은 표준오차와 기울기를 활용하여 계산한 $\mathrm{DDAC}$ 의 검출한계(MDL)는 Table 1에서 보는바와 같 이 $0.18 \mu \mathrm{g} / \mathrm{mL}$ 이었으며, 정량한계(LOQ: limit of quantitation)는 $0.54 \mu \mathrm{g} / \mathrm{mL}$ 이었다. 이때의 상관계수 $\left(\mathrm{r}^{2}\right)$ 는 0.996 이었다. 이 농도를 공기 포집량 $240 \mathrm{~L}$ 를 기준 으로 챔버 내 공기 중 농도로 환산하면 $\mathrm{MDL}$ 이 2.97 $\mu \mathrm{g} / \mathrm{m}^{3}, \mathrm{LOQ}$ 가 $8.92 \mu \mathrm{g} / \mathrm{m}^{3}$ 였다. 본 연구에서 실험동물 을 사용한 챔버 내 발생 예측 농도는 $70 ~ 900 \mu \mathrm{g} / \mathrm{m}^{3}$ 범

Table 1. Linearity and detection limit of DDAC analysis by ion chromatography

\begin{tabular}{cccccc}
\hline $\begin{array}{c}\text { Range } \\
(\mu \mathrm{g} / \mathrm{mL})\end{array}$ & $\mathrm{r}^{2}$ & $\mathrm{SE}$ & Slope & $\begin{array}{c}\text { MDL } \\
(\mu \mathrm{g} / \mathrm{mL})\end{array}$ & $\begin{array}{c}\mathrm{LOQ} \\
(\mu \mathrm{g} / \mathrm{mL})\end{array}$ \\
\hline $0 \sim 20$ & 0.997 & 0.358 & 447.8 & 0.18 & 0.54 \\
\hline
\end{tabular}

MDL: Method Detection Limit, LOQ: Limit of Quantitation, SE: Standard Error 
Table 2. Desorption efficiency and repeatability of DDAC analysis

\begin{tabular}{ccccccc}
\hline \hline & \multicolumn{3}{c}{ XAD-2 resin } & & \multicolumn{2}{c}{ Silica gel } \\
\cline { 1 - 3 } $\begin{array}{c}\text { Loading } \\
\text { amount }(\mu \mathrm{g})\end{array}$ & $\begin{array}{c}\text { Mean } \\
(\mu \mathrm{g} / \mathrm{mL})\end{array}$ & $\begin{array}{r}\text { Recovery } \\
(\%)\end{array}$ & $\begin{array}{c}\text { RSD } \\
(\%)\end{array}$ & & $\begin{array}{c}\text { Mean } \\
(\mu \mathrm{g} / \mathrm{mL})\end{array}$ & $\begin{array}{c}\text { Recovery } \\
(\%)\end{array}$ \\
\hline+19.2 & 3.6 & 74.4 & 9.6 & & 0.47 & 9.8 \\
+48 & 11.8 & 98.1 & 9.1 & & 0.57 & 4.8 \\
+96 & 21.8 & 90.8 & 5.7 & & 1.03 & 4.3 \\
\hline
\end{tabular}

Table 3. Mean concentration and reproducibility of DDAC generation in whole body inhalation chamber during 9 working days

\begin{tabular}{lccc}
\hline \hline & \multicolumn{3}{c}{ Concentration of DDAC $\left(\mathrm{mg} / \mathrm{m}^{3}\right)$} \\
\cline { 2 - 4 } & Low & Medium & High \\
\hline Mean & 71.5 & 225.5 & 906.3 \\
SD & 30.2 & 65.3 & 249.6 \\
RSD & $42 \%$ & $29 \%$ & $28 \%$ \\
Dilution factor & 0.32 & 0.25 & - \\
\hline
\end{tabular}

SD: Standard Deviation, RSD: Relative Standard Deviation

위로, 이 분석 방법은 최저 농도군 챔버의 예측 농도인 $70 \mu \mathrm{g} / \mathrm{m}^{3}$ 농도 수준의 DDAC의 분석에 적절하였다.

챔버 내 기중에서 XAD-2 resin과 silica gel 두 종류 의 흡착제를 사용하여 흡착시킨 DDAC의 탈착효율을 검증하였다. Table 2와 같이 아세토니트릴로 탈착한 탈착효율은 XAD-2 resin에서 74.4 98.1\%, silica gel에 서 4.3 9.8\%로 XAD-resin의 탈착효율이 silica Gel에 비하여 우수한 것으로 나타나 이 후의 실험에서는 흡 착제로 XAD-2 resin을 사용하였다. $\mathrm{DDAC}$ 의 일간분 석 결과는 blank에서부터 $20 \mu \mathrm{g} / \mathrm{mL}$ 까지의 농도 수준 에서 데이터 값이 모두 재현성 있는 결과를 얻을 수 있었으며, $\mathrm{RSD}$ 의 평균값은 $7.8 \%$ 였다.

전신 흡입노출 챔버 내에 발생시킨 $\mathrm{DDAC}$ 에어로 졸을 9일 동안 XAD-2 resin에 흡착시켜 분석한 결과 를 Table 3에 나타냈다. DDAC 에어로졸의 9일간 농 도 변이는 저농도 챔버에서 $42 \%$, 중농도 챔버에서 $29 \%$, 고농도 챔버에서 $28 \%$ 로 측정되었다. 이는 분석방 법에 대한 오차 뿐 아니라, 희석용 청정공기 혼합율, 미 스트 발생장치의 유량, 거품의 발생 정도 등에 따른 에어로졸 발생의 일간 오차가 반영되어 있다. 실험동 물을 사용한 흡입노출 시험에서 매일의 모니터링 결 과로부터 구한 노출량을 총 누적노출량으로 환산하게 된다. 따라서 본 연구에서 제시한 포집 방법과 분석조 건은 실험동물을 사용한 흡입독성 시험에 활용해서 $\mathrm{DDAC}$ 에어로졸의 농도 모니터링에 적용할 수 있을
것이다.

Nunez 등은 LC-MS를 이용하여 4급 암모늄 계열 의 물질들을 검출한계 $1.0 \sim 2.0 \mu \mathrm{g} / \mathrm{L}$ 수준으로 분석하 였다. 본 연구에는 전신 흡입노출 챔버라는 통제 환경 내에서 실험동물 폭로기간 동안 수시로 농도 모니터 링이 필요하다는 점에서 검출감도는 LC-MS보다 떨어 지더라도 노출 농도는 충분히 분석할 수 있으면서 LC$\mathrm{MS}$ 에 의한 방법보다 간편하고 시간과 노력이 덜 소모 되는 방법의 개발이 필요하였다. 이온크로마토그라피의 $250 \mathrm{~mm}$ 의 분석용 컬럼(IonPac CG12A $4 \times 250 \mathrm{~mm}$ )을 사 용했을 때 $\mathrm{DDAC}$ 의 컬럼내 머무름 시간은 25 분 이상 으로 1 회 분석에 소요되는 시간은 30 분이었다. 그러나 가드컬럼(IonPac CG12A $4 \times 50 \mathrm{~mm}$ )을 분석용 컬럼으 로 사용하면 $\mathrm{DDAC}$ 의 용출시간은 약 2.1 분으로 짧은 컬럼을 사용하여 분석시간을 5 분 이내로 줄일 수 있 어서 당일 포집된 시료에 대해 신속한 모니터링이 가 능하였다.

또한 분석법의 감도는 최저 농도 수준의 챔버 내 농도를 유의하게 검출할 수 있는 수준인지 검토하였 다. 본 연구에서 개발한 분석법의 감도는 공기 포집량 $240 \mathrm{~L}$ 를 기준으로 챔버 내 공기 중 농도로 환산하면 $\mathrm{MDL}$ 이 $2.97 \mu \mathrm{g} / \mathrm{m}^{3}$, LOQ가 $8.92 \mu \mathrm{g} / \mathrm{m}^{3}$ 로 전신 흡입 노출 챔버 내 최저농도 수준인 약 $70 \mu \mathrm{g} / \mathrm{m}^{3}$ 을 분석하 기에 충분하였다.

Garrod 등 ${ }^{10}$ 은 고압 스프레이 작업에서 살균제의 직 업적 노출을 모니터링하기 위하여 Tenax 흡착튜브를 사용하여 $\mathrm{DDAC}$ 를 포함한 4급 암모늄 계열 화합물과 기타 혼합 살균제를 포집하였다. 분석을 위하여 탈이온 수로 탈착한 후 4급 암모늄 계열 화합물 총량으로써 염소이온 농도로 정량하였다. 고압 스프레이 살균제 도 포 작업에서의 4 급 암모늄 계열의 노출량은 평균 $4.33 \sim 1320 \mathrm{mg} / \mathrm{m}^{3}$ 으로 보고하였다. 그러나 저자 등이 밝힌 것처럼 개별 물질 자체를 분석한 것이 아니라 염 소이온 총량으로서 간접적으로 정량하였기 때문에 다 른 소스에 의한 오염, 예를 들면 땀의 소금 등에 의해 염소이온 총량이 과대평가될 수 있음을 시사하였다.

Vincent 등1은 실내 공기 중 4급 암모늄 화합물의 포집과 분석을 위하여 간접 흡광 크로마토그라피법 (Indirect Photometric Chromatography, IPC)을 적용하 였다. 즉, 발색단이 없는 $\mathrm{DDAC}$ 를 검출하기 위하여 발색단이 풍부한 방항족 4급 염을 HPLC 이동상에 첨 가하여 높은 바탕선을 유지하고 DDAC가 용출되면서 나오는 마이너스 피크를 이용하여 정량하는 방법이다. 그러나 IPC법에 의한 LOD는 $100 \mu \mathrm{g} / \mathrm{mL}$ 로 너무 높아 
시료의 분석에 적용하기에는 부적절하였다.

이상의 결과로 볼 때 본 연구에서 제시한 이온크로 마토그라프를 사용한 $\mathrm{DDAC}$ 에어로졸의 분석법은 실 험동물을 사용한 전신 흡입노출 챔버 내의 DDAC 모 니터링에 적용이 가능할 것으로 판단되며, 향후 직업적 에어로졸 살균제 노출 근로자의 안전 관리를 위한 $\mathrm{DDAC}$ 의 유해성 평가에 활용될 수 있을 것으로 사료 된다.

\section{5. 결 론}

전신 흡입노출 챔버 내에 분무시킨 $\mathrm{DDAC}$ 에어로 졸 입자의 분석을 위하여 먼저 챔버 내 $\mathrm{DDAC}$ 에어 로졸의 입자 분포를 분석하였으며 XAD-2 resin 흡착 제를 이용하여 동물의 호흡기 위치에서 챔버 내 공기 를 포집하였다. 포집한 시료는 아세토니트릴로 탈착하 여 전도도 검출기를 연결한 이온크로마토그라프로 분 석하였으며 분석에 소요되는 시간은 5 분 이내였다. 제 시한 분석법의 감도는 공기 포집량 $240 \mathrm{~L}$ 를 기준으로 챔버 내 공기 중 농도로 환산하면 $\mathrm{MDL}$ 이 $2.97 \mu \mathrm{g} /$ $\mathrm{m}^{3}, \mathrm{LOQ}$ 가 $8.92 \mu \mathrm{g} / \mathrm{m}^{3}$ 로 흡입노출 챔버 내 최저농도 수준인 약 $70 \mu \mathrm{g} / \mathrm{m}^{3}$ 을 분석하기에 충분하였다.

따라서, 본 연구에서 제시한 이온크로마토그라피를 사용한 $\mathrm{DDAC}$ 에어로졸의 분석법은 실험동물을 사용 한 전신 흡입노출 챔버 내의 신속, 정확한 DDAC 모 니터링에 적용이 가능하다고 판단된다.

\section{참고문헌}

1. Official Journal of the European Union, Commission Regulation(EC) No. 1451/2007, http://eur-lex.europa. eu/JOIndex.do?ihmlang=en, Assessed 11 December 2011.
2. United States Environmental Protection Agency, Decision for Aliphatic Alkyl Quaternaries, http://www.regulations.gov/, Assessed August 2011.

3. Ministry of Environment, 3rd Report on Circulating Chemical List, Seoul, Korea, 2007.

4. Korea Occupational Safety and Health Agency, Material Safety Data Sheet database, http://www.kosha.or. kr/bridge?menuId=69, Assessed Mar 2012.

5. California Environmental Protection Agency, Department of Pesticide Regulation, http://www.cdpr.ca.gov/ docs/risk/toxsums/toxsumlist.htm, Assessed July 2011.

6. A. Ohnuma, T. Yoshida, H. Tajima, T. Fukuyama, K. Hayashi, S. Yamaguchi, R. Ohtsuka, J. Sasaki, J. Fukumori, M. Tomita, S. Kojima, N. Takahashi, Y. Takeuchi, M. Kuwahara, M. Taked, T. Kosaka, N. Nakashima and T. Harada, Experimental and Toxicologic Pathology, 62, 643-651 (2010).

7. The Korean Society of Environmental Health and Toxicology, Environmental and Toxicology Forum Report on Humidifier Biocide, Seoul, Korea, 2011.

8. United States Environmental Protection Agency, Recommendations for and Documentation of Biological Values for Use in Risk Assessment, http://cfpub.epa.gov/ ncea/cfm/recordisplay.cfm?deid=34855, Assessed May 2001.

9. O. Nunez, E. Moyano and M. T. Galceran, J. Chromatography A, 1058, 89-95 (2004).

10. A. N. Garrod, D. A. Rimmer, L. Robertshaw and T. Jones, Ann. Occup. Hyg., 42(3), 159-165 (1998).

11. G. Vincent, M. C. Kopferschmitt-Kubler, P. Mirabel, G. Pauli and M. Millet, Environ. Monit. Assess., 133, 2530 (2007). 